\title{
Game Research on Property Right Evolution of Small Water Conservancy Projects under the Conflict of Multi-Stakeholders
}

\author{
Qu Shengteng ${ }^{1, a}$, Zhang Yang ${ }^{2, b}$ \\ ${ }^{1}$ Business school of Hohai University Nanjing city, China \\ ${ }^{2}$ Business school of Hohai University Nanjing city, China
}

\begin{abstract}
The property right of small water conservancy projects (hereinafter referred to as SWCP) currently can be defined as three different forms: public property rights, private property rights, and a combination of public and private property rights. The main participants are the government, farmers, and other organizations. The interests and demands of different subjects are different, so the property rights structure of the SWCPs are also different. In order to explore the evolutionary law of the property right structure of SWCPs in the case of conflicting demands of multiple stakeholders, a game model for the evolutionary law of each main body of SWCPs was proposed in this paper. By analyzing the feasibility of the game of multi-stakeholder appeal conflicts, a multi-stakeholder game model was established. The game and evolution of each stakeholder were analyzed, and the evolution of the property rights of SWCPs under the game of each subject was simulated and analyzed. The research results show that if the incentives and constraints of cooperation between farmers and cooperatives, associations and other organizations are greater than the cost of cooperation, farmers will participate in the cooperation and invest in elements actively, thus promoting the integration of elements, thereby contributing resource complementarity among participants and leaving more cooperation surplus. If the benefits of cooperation between the government and farmer organizations plus the total benefits of the incentive and restraint mechanism are greater than the total cost of active cooperation, furthermore, the incremental benefits of the incentive and restraint mechanism are not lower than the incremental costs of participating in the cooperative, then, farmer organizations are easier to get succeed. The research results have certain reference significance for the option of the property rights and management modes of SWCPs.
\end{abstract}

\section{Introduction}

Water conservancy projects are important infrastructures that guarantee national economic development, social harmony and public safety. At the National Video and Telephone Conference of Winter and Spring Farmland Water Conservancy Infrastructure in November 2018, Premier Li Keqiang pointed out, "To ensure national food security and promote the development of modern agriculture, we should strengthen the infrastructure construction of farmland water conservancy, attach great importance to food crop production strategy based on farmland management and technological application. " The management of small water conservancy projects is directly related to the function of farmland water conservancy projects, and is important in the linkage of large, medium, small and micro water conservancy projects.

With the characteristics of a small scale and scattered distribution in the fields, small water conservancy projects are usually regarded as a typical public pond resource [12]. The maintenance and operation of SWCPs are more difficult, while the two aspects are directly related to the efficiency of agricultural income and water use, and they are crucial to food security and the development of rural economy. The structure of property rights refers to the composition of various property rights of assets. As the basis for the distribution of control rights, it plays a fundamental and decisive role in the governance and efficiency. From the perspective of the property rights structure of SWCPs, there are three forms [3]: public property rights, private property rights, or a combination of public and private property rights. The structure of property rights is the core of the institutional arrangements of cooperatives. Different property rights arrangements determine different organizational structures, incentive and restraint mechanisms, thereby affecting the efficiency of resource allocation. At present, the structure of SWCP property rights is unreasonable.

Therefore, this paper studies the evolution process of the property rights system of SWCPs under evolutionary game theory. Since there are multiple subjects with different demands involved in SWCPs, this paper focuses on the study of the evolutionary game of property rights of SWCPs under the conflicts of appeals of multistakeholders. First of all, the origin and development of evolutionary games are explained in this paper, the basic

aemail: paolom qst @163.com, bemail: zyang@hhu.edu.cn 
concepts of evolutionary games were defined, the feasibility of evolutionary games of multi-stakeholder appeal conflicts and the evolutionary games of various stakeholders involved in SWCPs are analyzed. A simulation analysis is conducted to provide a basis for determining the property right structure of SWCPs.

\section{Literature Review}

A lot of research has been made on the application of evolutionary game theory. Traditional game theory assumes that the participants in the game are completely rational and they always view maximizing benefits as the final goal. And they are assumed to have the ability to judge and make decisions to maximize benefits. This is an excessive idealization of reality and cannot explain the irrational behavior tendency of the subject. Smith and Price [4] proposed the Evolutionary Stable Strategy (ESS), which freed people from the rational trap of game theory and promoted evolutionary game theory. Weibull [5] summarized the evolutionary game theory systematically and completely. Aoki [7] pointed out that game equilibrium can explain the origin and implementation of the system from an endogenous perspective. The model of repeated game is mainly used to analyze systems such as contracts, norms, and governance structures that require a clear definition of implementation mechanisms. Compared with repeated game, the advantage of evolutionary game is that it believes that the rationality of participants is very limited and abandons the requirement of traditional game players to be completely rational. The behavior of participants in the evolutionary game is affected by the actions, experiences of others and random events, as well as the result with superior efficiency. Friedman [8] applied evolutionary games to the economic field, and discussed dynamic systems with practical value in detail. Kosfeld [9] established an evolutionary game model of abnormal shopping time in German supermarkets. Nvborg and Rege [10] studied the formation of social norms of smoking behavior that takes into account the feelings of others under evolutionary game theory. Jasmina and John [11] studied the performance of three different learning rules imitating human behavior in the game of public goods. Daniel [12] studied four different types of prisoner's dilemma games, and pointed out the evolution and information requirements of the four prisoners' dilemmas to cooperate. Josef and William [13] discussed the evolutionary game with random perturbation benefits and applied it to the game study of the number of people. Feng Lei [14] studied the complex interaction between cognition, informal constraints and institutional changes based on the perspective of evolutionary games. These studies provided significant references for the research of game among the stakeholders of SWCPs.

The research results mentioned above mainly focus on the evolutionary game model, but few of them researched the application in actual scenarios or on the stakeholder and property right evolution of SWCPs. Evolutionary game theory method is adopted in this paper to establish a multi-stakeholder evolutionary game model for SWCPs to analyze the game behavior between farmers and farmers, between farmers and water organizations, and between water organizations and governments under conflict of interest. The evolution law of SWCP property rights under the conflict of interest subjects provides a basis for the determination of SWCP property rights and the choice of management mode.

The rest of this paper is as follows. Part 3 describes the core idea of evolutionary game theory, and constructs the replicated dynamic equation model of evolutionary game theory. Part 4 analyzes the game behaviors between different stakeholders through the evolutionary game theory model, and draws the law of the evolution of the property rights of SWCPs under the conflicts of the appeals of different stakeholders. The last part is summary and relevant conclusions.

\section{Model of Evolutionary Game Theory}

Based on game theory, evolutionary game theory is a new theory that combines game theory with dynamic evolutionary theory. It draws on the theoretical viewpoints of biology and uses bounded rationality as a starting point to explain the dynamic process of biological evolution and explain the evolution of biological species by studying group behavior. Evolutionary game theory has wide applications in management and economics, and it is often used to study institutional changes and industrial evolution.

Evolutionary stability strategy and replication dynamics are two core concepts in the evolutionary game model. Evolutionary stability strategy means that in the process of the game, due to the bounded rationality of the two parties, it is impossible for the game party to find the optimal strategy and optimal equilibrium point from the beginning. Therefore, they need to learn in the process of the game, and those with strategic mistakes will imitate others favorable strategies and improve their own strategies. After a period of imitation and improvement, all parties will tend to a stable strategy. The replication dynamic is actually a dynamic differential equation describing the frequency or frequency of a particular strategy used in a population [14], which can be expressed by the following formula:

$$
\frac{\mathrm{d}_{x i}}{d_{t}}=x_{i}\left[\left(u_{s_{i}}, x\right)-u(x, x)\right]
$$

In the above formula, $x_{i}$ is the proportion or probability of adopting a pure strategy $\mathrm{S}_{i}$ in a population, $\left(u_{s_{i}}, x\right)$ is the fitness of the pure strategy, and $u(x, x)$ is the average fitness.

When evolutionary game models are applied to analyze actual problems, they are based on certain basic assumptions, which are also the premise of establishing the evolutionary game model. The bounded rationality of the players is the basic assumption of the evolutionary game theory.

Japanese scholars Aoki and Okuno Fujiwara [15] believe that bounded rationality consists of three elements, namely inertia, lack of foresight, and trial and error. Selten 
[16] investigated the strategic interaction behavior of bounded rationality through experimental research methods, and the research showed that the behavior of bounded rationality was manifested as: superficial analysis of the situation, reciprocity and fairness. Therefore, bounded rationality is a rationality with many restrictions. In the actual evolutionary game modeling, the assumptions about the behavior of the players must be able to reflect the influence of bounded rationality.

The evolutionary game model is based on two aspects: selection and mutation. Selection should reflect the idea of survival of the fittest, that is, the strategy with higher pay will be selected and eventually survive; mutation reflects the idea of random selection, that is, the game individual Random methods choo In the management of small water conservancy projects, the main participants: the government, farmers, organizations (including cooperatives and associations of water users, etc.). They can be regarded as game participants with bounded rationality, and each has information with different quantity, and cost. This is the game of incomplete information, so their behavior has the nature of trial and error, and they are not considered to be the optimal decision under the condition of rational and complete information. The bounded rationality of each participant is mainly reflected in the limited cognition of the environment, the limited understanding of the information of other game participants, and the lag in responding to environmental changes. In the process of the game, each subject makes decisions through learning, imitation, and trial and error, so as to reach a kind of dynamic equilibrium. When the equilibrium is reached and how the equilibrium point is all depend on the conditions of parties, as well as changes in their relative positions and roles, and changes in the environment. The basic hypothesis of evolutionary game theory is that participants are bounded rationally. The use of evolutionary game theory can fully explain the dynamic equilibrium process of the game, as well as the diversity of the internal norms and governance structure of cooperatives. Aiming at the conditions for the emergence of an optimal balance of both fairness and efficiency, it can improve the organizational system, standardize the behavior of the main body, and improve the management performance of SWCPs.se different strategies from groups.

\section{Research Analysis and Discussion}

\subsection{Evolutionary Game Analysis of Farmers}

In the daily management of small water conservancy projects, many farmers are the same. They participate in the management process of cooperatives and associations of water users. And they have no great differences in the quantity and quality of resources, and the scale of production. It is assumed here that farmers are bounded rationally, and have limited computing and cognitive ability for the complexity and uncertainty of the economic environment. Their limited education makes their ability to collect, calculate and predict information is also very limited. The process of farmers participating in the game is a process of learning, imitating and trial and error.
Assuming that the group size of farmers is $n$, the total income of the cooperative is $\mathrm{R}$, and the total cost is $\mathrm{C}$, the income of a single farmer in the game is $r=R / n$, and the cost of a single farmer is $\mathrm{c}=\mathrm{C} / \mathrm{n}$. Select group members in a pairwise game randomly, and each farmer has two behavior strategies (positive cooperation and negative cooperation). It is assumed that positive cooperation is a large group strategy, and the proportion of the number of people who choose this strategy is $\mathrm{x}$, and negative cooperation is a mutation strategy. Choose this strategy The proportion of people is 1-x. At the same time, farmers are independent and can freely choose whether to join the organization. An incentive mechanism i and a restraint mechanism $b$ are also introduced to prevent negative cooperative behaviors of farmers.

Select farmer 1 and farmer 2 randomly to play the game. If both parties of the game cooperate actively, each farmer can obtain a profit of $\mathrm{r}-\mathrm{c}+\mathrm{i}$. If one party chooses to cooperate actively and the other party chooses to cooperate passively, it is assumed that the total revenue of cooperation is reduced to RP due to the decrease in the number of people actively cooperating. It means the total revenue RP of the cooperative is the result of the efforts of $\mathrm{x}$ proportion of participants. In order to simplify the calculation, the overall benefit is assumed proportional to the proportion of active cooperating members, that is, $\mathrm{RP}=\mathrm{xR}$, then the individual income at this time isrp $=R P / n=x r$. Assuming that the available resources of farmers are limited, the active partner does not increase the unit cost, and the passive partner chooses to invest nothing and "take a free ride", the active partner's profit is $\mathrm{xr}-\mathrm{c}+\mathrm{i}$; the passive partner's profit is $x r-b$; If both parties choose to cooperate negatively, each person can get a profit of $-b$. The game payout matrix of farmer 1 and farmer 2 is shown in the table below.

Table1. Game payment matrix between farmer 1 and farmer 2

\begin{tabular}{|c|c|c|c|}
\hline & & \multicolumn{2}{|c|}{ Farmer2 } \\
\hline & & $\begin{array}{c}\text { Active } \\
\text { cooperation } \mathrm{x}\end{array}$ & $\begin{array}{c}\text { Passive } \\
\text { cooperation1-x }\end{array}$ \\
\hline \multirow{4}{*}{$\begin{array}{c}\text { Farmer } \\
1\end{array}$} & $\begin{array}{c}\text { Active } \\
\text { cooperation } \mathrm{x}\end{array}$ & $\begin{array}{c}(\mathrm{r}-\mathrm{c}+\mathrm{i}, \mathrm{r}- \\
\mathrm{c}+\mathrm{i})\end{array}$ & $(\mathrm{xr}-\mathrm{c}+\mathrm{i}, \mathrm{xr}-\mathrm{b})$ \\
\cline { 2 - 4 } & $\begin{array}{c}\text { Passive } \\
\text { cooperation 1- } \\
\mathrm{x}\end{array}$ & $\begin{array}{c}(\mathrm{xr}-\mathrm{b}, \mathrm{xr}- \\
\mathrm{c}+\mathrm{i})\end{array}$ & $(-\mathrm{b},-\mathrm{b})$ \\
\hline
\end{tabular}

Because farmer 1 and farmer 2 are the same, their strategies and payment space are the same, so take farmer 1 as an example for evolution analysis.

Expected payment for active cooperation of farmer 1:

$$
\mathrm{U} 11=\mathrm{x}(\mathrm{r}-\mathrm{c}+\mathrm{i})+(1-\mathrm{x})(\mathrm{xr}-\mathrm{c}+\mathrm{i})
$$

Expected payment for negative cooperation of farmer 1 :

$$
\mathrm{U} 12=\mathrm{x}(\mathrm{xr}-\mathrm{b})-(1-\mathrm{x}) \mathrm{b}
$$

Expected payment for average cooperation of farmer 1:

$$
\mathrm{U} 1=\mathrm{x} \mathrm{U} 11+(1-\mathrm{x}) \mathrm{U} 12
$$

According to the game process of the evolutionary game, the replicated dynamic equation of farmer 1 within time $t$ can be listed as: 


$$
\begin{aligned}
& \frac{d x}{d t}=x\left(U_{11}-U_{1}\right)=x(1-x)\left(-2 r x^{2}+2 r x-c+i+b\right) \\
& \text { If } F(x)=\frac{d x}{d t}=x(1-x)\left(-2 r x^{2}+2 r x-c+i+b\right)=0, \\
& \text { Then : } \mathrm{x} 1=0, \quad \mathrm{x} 2=1, \quad x_{3}=\frac{1+\sqrt{1-\frac{2(c-i-b)}{r}}}{2}, \\
& x_{4}=\frac{1-\sqrt{1-\frac{2(c-i-b)}{r}}}{2}
\end{aligned}
$$

As we can see from the above, $\mathrm{r}>0, \mathrm{c}<\mathrm{r}, 0<\mathrm{x}<1$, so when $1-\frac{2(c-i-b)}{r} \geq 0$ and $c-i-b>0, \quad x_{3}>0, x_{4}<1$. The solutions of $\mathrm{x} 3$ and $\mathrm{x} 4$ are meaningful and both are equilibrium solutions. After solving, $\mathrm{c}-\mathrm{r} / 2<\mathrm{i}+\mathrm{b}<\mathrm{c}$ 。

Because $\mathrm{F}(\mathrm{x})=x(1-x)\left(-2 r x^{2}+2 r x-c+i+b\right)$, so:

$$
\mathrm{F}^{\prime}(\mathrm{x})=8 \mathrm{rx} 3-12 \mathrm{rx} 2+2(2 \mathrm{r}+\mathrm{c}-\mathrm{i}-\mathrm{b}) \mathrm{x}+(\mathrm{b}+\mathrm{i}-\mathrm{c})
$$

(1) When $x=0$, that is, all farmers adopt a negative cooperative attitude, then $F^{\prime}(x)=\mathrm{b}+\mathrm{i}-\mathrm{c}$. When $0<\mathrm{b}+\mathrm{i}<\mathrm{cr} / 2$, $\mathrm{F}^{\prime}(\mathrm{x})<0$, according to the expressions of $\mathrm{F}(\mathrm{x})$ and $\mathrm{F}^{\prime}(\mathrm{x})$, we know that $\mathrm{F}(\mathrm{x})$ is the first derivative, $\mathrm{F}^{\prime}(\mathrm{x})$ is the second derivative. When the first derivative is equal to 0 and the second derivative is less than 0 , the function has a maximum value, that is, the effect of farmers $u(x)$ increases monotonically on the left side of $u(0)$, and decreases monotonously on the right side of $u(0)$, So $u(0)$ is a maximum value. At this time, $x=0$ means that the proportion of choosing active cooperation strategies is 0 , which means the farmers in the professional farmer cooperatives all choose the "negative cooperation" strategy to achieve stable evolutionary equilibrium. When $\mathrm{c}-\mathrm{r} / 2<\mathrm{b}+\mathrm{i}<\mathrm{c}, \mathrm{F}^{\prime}(\mathrm{x})<0$, it can be known that the farmers in the professional farmer cooperatives all choose the "passive cooperation" strategy to achieve evolutionary stable equilibrium. When $\mathrm{b}+\mathrm{i}>\mathrm{c}, \mathrm{F}^{\prime}(\mathrm{x})>0$, when the first derivative is equal to 0 , and the second derivative is greater than 0 , the function has a minimum value, that is, $u(0)$ is the minimum at this time, and farmers may change the strategy when dissatisfied with the current situation, and this is not an evolutionary stable equilibrium.

(2) When $x=1$, that is, all farmers adopt the strategy of "active cooperation", and $\mathrm{F}^{\prime}(\mathrm{x})=\mathrm{c}-\mathrm{i}-\mathrm{b}$. When $0<\mathrm{b}+\mathrm{i}<\mathrm{c}-\mathrm{r} / 2$, $F^{\prime}(x)>0$, the farmer effect $u(1)$ is the minimum at this time, and the farmer will change the strategy through learning and imitation. This is not an evolutionary stable equilibrium. When $\mathrm{c}-\mathrm{r} / 2<\mathrm{b}+\mathrm{i}<\mathrm{c}, \mathrm{F}^{\prime}(\mathrm{x})>0$, at this time, the farmer effect $\mathrm{u}(1)$ is the minimum, and the farmer will change the strategy through learning and imitation. This is not an evolutionary stable equilibrium. When $b+i>c$, $\mathrm{F}^{\prime}(\mathrm{x})<0$, at this time, the farmer effect $\mathrm{u}(1)$ is the maximum, and the farmer will choose the strategy of "active cooperation" to reach an evolutionary stable equilibrium.

$$
\text { (3) When } x=\frac{1+\sqrt{1-\frac{2(c-i-b)}{r}}}{2} \text {, x represents the }
$$

proportion of farmers who choose the "active cooperation" strategy, and $0 \leq x \leq 1$, so equation (4-2) is meaningful only when the selection condition is $\mathrm{c}-\mathrm{r} / 2<\mathrm{i}+\mathrm{b}<\mathrm{c}$. At this time, $\mathrm{F}^{\prime}(\mathrm{x})<0$ means that farmers choose the "active cooperation" strategy to have the maximum effect. The farmers who originally adopted the "negative cooperation" strategy will learn and imitate the strategy of active cooperation farmers, so as to achieve an evolutionary stable equilibrium.

$$
x=\frac{1-\sqrt{1-\frac{2(c-i-b)}{r}}}{2}
$$

(4) When $2 \quad$, since $0 \leq \mathrm{x} \leq 1$, the equation (4-2) is meaningful only when the condition $\mathrm{c}-\mathrm{r} / 2<\mathrm{i}+\mathrm{b}<\mathrm{c}$. At this time, $\mathrm{F}^{\prime}(\mathrm{x})>0$, indicating that the effect of participating in active cooperation of farmers $\mathrm{u}(\mathrm{x})$ is the minimum, and this is not an evolutionary stable equilibrium.

According to the above replication dynamic models, the evolutionary game among farmers can be explained:

From the inequality $0<\mathrm{b}+\mathrm{i}<\mathrm{c}-\mathrm{r} / 2$, two inequalities $c>r / 2$ and $c-(b+i)>r / 2$ can be derived. They show that the benefits of participating in farmers' professional cooperatives are very low or the cost is high. In the inequality, the cost of cooperation exceeds half of the benefits of cooperation; if the sum of incentives for active cooperation and constraints on negative cooperation is very small, the cost of cooperation is so small. After subtracting the sum of incentives and constraints, it is still higher than half of the gain. At this time, the game between farmers is a "prisoner's dilemma". Even at the beginning of the cooperation, some farmers choose active cooperation strategies, but after a long period of learning and imitating, more and more farmers will eventually choose passive cooperation.

From $\mathrm{c}-\mathrm{r} / 2<\mathrm{b}+\mathrm{i}<\mathrm{c}$, it can be deduced that $\mathrm{c}-(\mathrm{b}+\mathrm{i})<\mathrm{r} / 2$, that is, the cooperation cost minus the sum of incentives and constraints is less than half of the gain. There are two completely different evolutionary stable equilibriums in the behavior of all farmers. The two balanced results are closely related to the initial and past behaviors of farmers. If most of the farmers are reluctant or have a "free rider" mentality at the initial cooperation, the cooperation between farmers will easily fall into a "prisoner's dilemma". However, if most people choose the active cooperation strategy at the initial cooperation, the proportion of farmers who choose the active cooperation

strategy will gradually converge to $x=\frac{r}{2}$. The cooperatives and associations must meet the interests and practical needs of farmers, strengthen and cultivate the spirit of cooperation, deepen farmers' cognition of professional cooperatives of farmers, and motivate the desire of cooperation.

$b+i>c$ shows that the incentives and constraints of cooperation are greater than the cost of cooperation, and farmers can obtain considerable incentive benefits from long-term active cooperation. It shows the importance of designing incentive and restraint mechanisms in the organization. A good incentive and restraint mechanism will increase the income expectations of farmers, affect the 
cooperative behavior of farmers positively, and bring notable results.

\subsection{Evolutionary game analysis and simulation of farmers and organizations like cooperatives, associations of water user}

Compared with ordinary farmers, organizations such as cooperatives and water user associations have scarce resources, such as capacity, experience, information, funds, and resource allocation rights. Due to the differences in the resources and capabilities of the two parties, the status and role of each participant in the organization are also different, forming a relatively strong party and a relatively weak party. In this paper, organizations such as cooperatives and water user associations that are relatively in an advantaged position are referred to as group 1, and ordinary farmers who are relatively in a disadvantaged position are referred to as group 2.

The behavioral strategies of the strong group 1 include (active cooperation, passive cooperation). Its active cooperation is manifested in actively increasing factor input, improving internal systems, and actively disclosing information, etc., while passive cooperation is manifesting in reducing factor input, transfer costs, high commissioning and agency costs, as well as internal deprivation and so on. Behavioral strategies of group 2 include (active cooperation, negative cooperation), whose active cooperation is manifested as diligence and active participation in supervision; negative cooperation is manifested by laziness, free ride behavior and ignorance towards deprivation.

Assuming that the total cost of the organization's factor input is $C, \beta 1$ and $\beta 2$ represent the proportions of the input elements of the strong group 1 and the disadvantaged group 2 respectively, and $0<\beta 2<\beta 1$; that is, the input of the members of the weak group is less than the input of the members of the strong group, and $\beta 2+\beta 1=1$. In order to simplify the calculation, the profit of the strong group 1 and the weak group 2 under the (passive cooperation, negative cooperation) strategy is supposed to be their respective profits i1 and i2 without participating in the organization.

Assuming that both the strong group 1 and the disadvantaged group 2 "actively cooperate", they will generate additional income $\mathrm{R}, R_{l}$ and $R_{2}$ respectively represent the additional income shared by the strong group and the disadvantaged group under the principle of "propoor". $R=R_{1}+R_{2}$. At this time, the profit of group 1 is $i_{1}+R_{1}-\beta_{1} C$, and the profit of group 2 is $i_{2}+R_{2}-\beta_{2} C$.

If group 1 chooses the "active cooperation" strategy and group 2 chooses the "negative cooperation" strategy, the organization will not generate additional income $\mathrm{R}$ due to joint efforts, then the profit $i_{2}$ of group 2 remains unchanged, and the investment $\beta_{l} C$ of group 1 cannot be recovered, The profit becomes $i_{1}-\beta_{l} C$. If group 2 chooses the "active cooperation" strategy and group 1 chooses the "negative cooperation" strategy, the organization will not generate additional income $\mathrm{R}$ due to joint efforts, then the profit il of group 1 remains unchanged, and the investment $\beta 2 \mathrm{C}$ of group 2 cannot be recovered. The profit becomes $i_{2}-\beta_{2} C$.

Suppose that the probability of strong group 1 choosing "active cooperation" in the initial state is $\mathrm{x}$, and the probability of choosing "negative cooperation" is 1-x; the probability of weak group ordinary farmers 2 choosing "active cooperation" strategy is $\mathrm{y}$, and choosing "negative cooperation" The probability of the strategy is $1-y$. The game payout matrix of the strong group 1 and the weak group 2 is shown in the table below.

Table2. The game payout matrix of the strong player 1 and the weak player 2

\begin{tabular}{|c|c|c|c|}
\hline & & \multicolumn{2}{|c|}{ Disadvantaged Group 2 } \\
\hline & & $\begin{array}{c}\text { Active } \\
\text { corporation y }\end{array}$ & $\begin{array}{c}\text { Passive } \\
\text { corporation 1-y }\end{array}$ \\
\hline \multirow{3}{*}{$\begin{array}{c}\text { Advantaged } \\
\text { Group 1 }\end{array}$} & $\begin{array}{c}\text { Active } \\
\text { corporation } \mathrm{x}\end{array}$ & $\begin{array}{c}\mathrm{i} 1 \mathrm{C}, \mathrm{i} 2+\mathrm{R} 2- \\
\beta 2 \mathrm{C})\end{array}$ & $(\mathrm{i} 1-\beta 1 \mathrm{C}, \mathrm{i} 2)$ \\
\cline { 2 - 4 } & $\begin{array}{c}\text { Passive } \\
\text { corporation } \\
1-\mathrm{x}\end{array}$ & $\begin{array}{c}(\mathrm{i} 1, \mathrm{i} 2- \\
\beta 2 \mathrm{C})\end{array}$ & $(\mathrm{i} 1, \mathrm{i} 2)$ \\
\hline
\end{tabular}

Based on this, analysis of the replication dynamic model is shown as following:

Advantaged group 1 chooses to cooperate actively, and its expected payment depends on the choice of farmers in group 2: $\mathrm{U}_{11}=y\left(i_{1}+R_{I}-\beta_{I} C\right)+(1-y)\left(i_{l}-\beta_{1} C\right)$

The advantaged subject 1 chooses the expected payment of negative cooperation:

$$
\mathrm{U}_{12}=y i_{1}+(1-y) i_{1}
$$

Therefore, the average expected payment of the advantaged subject:

$$
\mathrm{U}_{1}=x \mathrm{U}_{11}+(1-x) \mathrm{U}_{12}
$$

In the same way, the average expected payment of disadvantaged group 2 can be obtained:

$$
\mathrm{U}_{2}=y \mathrm{U}_{21}+(1-y) \mathrm{U}_{22}
$$

Suppose that when two groups participate in the game, their behavior is "bounded rationality", but they will recognize the shortcomings of past strategies and adjust their behavior strategies through continuous learning, imitation, and trial and error. The dynamic adjustment equation for the replication of group 1 and group 2 within time $t$ can be obtained as:

$$
\begin{gathered}
\mathrm{F}(x)=\frac{d x}{d t}=x\left(\mathrm{U}_{11}-\mathrm{U}_{1}\right)=x(1-x)\left(R_{l} y-\beta_{l} C\right) \\
\mathrm{F}(y)=\frac{d y}{d t}=y\left(\mathrm{U}_{21}-\mathrm{U}_{2}\right)=\mathrm{y}(1-y)\left(R_{2} x-\beta_{2} C\right)
\end{gathered}
$$

If $\mathrm{F}(\mathrm{x})=0, \mathrm{~F}(\mathrm{y})=0$, then: $\mathrm{x}_{1}=0, \mathrm{x}_{2}=1, \mathrm{x}_{3}=\beta_{2} \mathrm{C} / \mathrm{R}_{2} ; \mathrm{y}_{1}=0$, $\mathrm{y}_{2}=1, \mathrm{y}_{3}=\beta_{1} \mathrm{C} / \mathrm{R}_{1}$ 。

From this, solutions that make it possible for group 1 and group 2 to reach an evolutionary stable state are: $\mathrm{S}_{1}$

$(0,0), \quad S_{2}(1,0), \quad S_{3}(0,1), \quad S_{4}(1,1)$ and $S_{5}\left(\beta_{2} C / R_{2}\right.$, $\left.\beta_{1} C / R_{1}\right)$. This paper adopts the method proposed by Friedman (1991), which is the stability of the equilibrium point can be obtained from the local stability analysis of the Jacobian matrix of the system. Calculate the partial derivatives of $\mathrm{x}$ and $\mathrm{y}$ with respect to $\mathrm{F}(\mathrm{x})$ and formula $\mathrm{F}(\mathrm{y})$ respectively, and get the Jacobian Matrix J: 


$$
J=\left|\begin{array}{ll}
(1-2 x)\left(R_{1} y-\beta_{1} C\right) & x(1-x) R_{1} \\
y(1-y) R_{2} & (1-2 y)\left(R_{2} x-\beta_{2} C\right)
\end{array}\right|
$$

The trail of the matrix :

$$
\operatorname{TRAL}(\mathrm{J})=(1-2 x)\left(R_{1} y-\beta_{1} C\right)+(1-2 y)\left(R_{2} x-\beta_{2} C\right)
$$

The local stability of these 5 equilibrium points is judged according to the local stability analysis method, and the analysis results are shown in the table below.

Table3. Stability analysis table of local equilibrium point

\begin{tabular}{|c|c|c|c|c|c|}
\hline Equilibrium point & Determinant of J & Sign & Trail J & Sign & Stability \\
\hline $\mathrm{S} 1(0,0)$ & $\beta 1 \beta 2 \mathrm{C} 2$ & Positive & $-(\beta 1+\beta 2) \mathrm{C}$ & Negative & Stable \\
\hline $\mathrm{S} 2(1,0)$ & $\beta 1 \mathrm{C}(\mathrm{R} 2-\beta 2 \mathrm{C})$ & Positive & $\mathrm{R} 2+(\beta 1-\beta 2) \mathrm{C}$ & Positive & Unstable \\
\hline $\mathrm{S} 3(0,1)$ & $\beta 2 \mathrm{C}(\mathrm{R} 1-\beta 1 \mathrm{C})$ & Positive & $\mathrm{R} 1-(\beta 1-\beta 2) \mathrm{C}$ & Positive & Unstable \\
\hline $\mathrm{S} 4(1,1)$ & $(\mathrm{R} 1-\beta 1 \mathrm{C})(\mathrm{R} 2-\beta 2 \mathrm{C})$ & Positive & $(\beta 1+\beta 2) \mathrm{C}-\mathrm{R} 1-\mathrm{R} 2$ & Negative & Stable \\
\hline $\mathrm{S} 5(\beta 2 \mathrm{C} / \mathrm{R} 2, \beta 1 \mathrm{C} / \mathrm{R} 1)$ & $-(\mathrm{R} 2-\beta 2 \mathrm{C})(\mathrm{R} 1-\beta 1 \mathrm{C}) / \mathrm{R} 1 \mathrm{R} 2$ & Negative & 0 & & Saddle point \\
\hline
\end{tabular}

From the above table, among the five local equilibrium points, the points $\mathrm{S} 1(0,0)$ and $\mathrm{S} 4(1,1)$ have local stability, corresponding to the evolutionary stability strategy ESS of the total population. The point $\mathrm{S} 1(0,0)$ indicates that when the total population reaches evolutionary stability, the individuals in the two types of subgroups all choose the "negative cooperation" strategy. At this time, "negative cooperation" is the only evolutionary stable strategy. Point S4 $(1,1)$ indicates that when the total group reaches evolutionary stability, the individuals in the two types of subgroups adopt the "active cooperation" strategy. At this time, "active cooperation" is the only evolutionary stable strategy. The points S2 $(1,0), \mathrm{S} 3(0,1)$ and S5 $(\beta 2 \mathrm{C} / \mathrm{R} 2$, $\beta 1 C / R 1)$ are the unstable equilibrium points of the evolution system, and the point S5 is the saddle point.

The evolutionary game of the stable equilibrium point is analyzed based on the above analysis.

The calculation of the evolutionary equilibrium between the strong group 1 and the weak group 2 obtains two stable equilibrium solutions: S1 and S4, both of which are with local stability. The stable equilibrium point shows that the initial willingness to cooperate and the degree of effort after the cooperation have an important influence on the success of the cooperation.

Point S1 shows that neither the strong or the disadvantaged has a strong initial willingness to cooperate. The strong group has another plan, and the farmers want to "take a free ride"; or everyone has a certain desire to cooperate at the beginning, but one party chooses to be lazy or "take a free ride" in the process of cooperation. In the short term, the result of the game between the two parties is that one party has reached the state of "maximum profit", and the other party not only does not increase revenue, but also bears additional costs. In the long run, through learning and imitating, the party with a disadvantaged interest will also choose a "negative cooperation" strategy to avoid more losses. Gradually, everyone abandoned the "active cooperation" strategy and turned to the "negative cooperation" strategy, which eventually harmed the development of cooperatives, associations of water users and other organizations, and even led to their dissolution.

Point S4 $(1,1)$ shows that both the advantaged and the disadvantaged are aware that cooperation can complement resources and increase benefits, so both parties have a strong desire to cooperate. The two sides play their comparative advantages through specialized division of labor. For agricultural production, farmers own land and labor resources, and large households, enterprises, and supply and marketing cooperatives have experience, capital, information, technology, and market channels. Through cooperation, the two parties can learn from each other's strengths and make full use of resources to achieve the Pareto Optimality of production. Since cooperation can bring more surplus, the distribution of cooperation surplus is reasonable and there is no internal deprivation problem. Everyone learns the strategy of "active cooperation", and finally the evolutionary game between the two parties converges to point S4 $(1,1)$.

It can be deduced from the calculation that the points $\mathrm{S} 2(1,0), \mathrm{S} 3(0,1)$ are the unstable equilibrium points of the evolution system, and S5 $(\beta 2 \mathrm{C} / \mathrm{R} 2, \beta 1 \mathrm{C} / \mathrm{R} 1)$ is the saddle point. The following is an analysis based on the evolution trend diagram of a large number of random individuals infinitely repeated games.

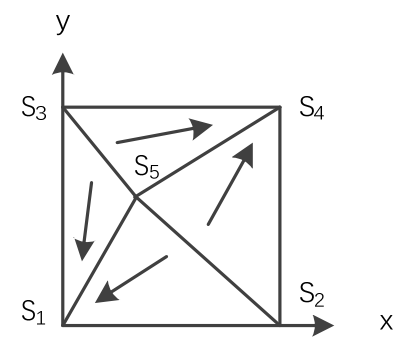

Fig 1. Dynamic diagram of game replication between the advantaged and disadvantaged groups

As can be seen from the above figure, the broken line composed of points $S_{2}, S_{3}$ and $S_{5}$ is the dividing line for individuals to choose different strategies after the group dynamic evolution game reaches equilibrium. It divides the cooperative group evolution space into two regions $\mathrm{S}_{1} \mathrm{~S}_{2} \mathrm{~S}_{5} \mathrm{~S}_{3}$ and $\mathrm{S}_{3} \mathrm{~S}_{5} \mathrm{~S}_{2} \mathrm{~S}_{4}$. In the $\mathrm{S}_{1} \mathrm{~S}_{2} \mathrm{~S}_{5} \mathrm{~S}_{3}$ area, the system converges to the point $S_{1}(0,0)$, and the "negative cooperation" strategy becomes an evolutionary stable strategy; in the $\mathrm{S}_{3} \mathrm{~S}_{5} \mathrm{~S}_{2} \mathrm{~S}_{4}$ area, the system converges to the $\mathrm{S} 4(1,1)$ point, and the "active cooperation" strategy is the only evolutionary stability Strategy. It can be seen that the long-term game will evolve in two directions from the random selection of game objects from the two groups participating in the cooperation: all members of the group will either choose "passive cooperation" or all choose "active cooperation". In the replication dynamic graph, at 
which point the two groups will choose "active cooperation" or "negative cooperation" depends on the position of saddle point $\mathrm{S}_{5}$. Based on this, the following two important conclusions can be drawn:

First, the rational allocation of resources and cost sharing are important conditions for cooperation. Sharing costs reasonably and together is extremely important. It is conducive to attracting investment from ordinary farmers to form a good property right structure. It can strengthen the mutual connection between cooperative members and form a "risk sharing and benefit sharing" community of interests, which is to realize the smooth progress of cooperation. Important guarantee. Second, the distribution of cooperation surplus is a key factor related to the success or failure of cooperation. Cooperation is more beneficial to all parties than non-cooperation is the first condition for the emergence of cooperation. The size of "cooperative surplus" is often an important consideration used to measure the efficiency of cooperative systems. The key problem to be solved by the cooperative game is how to distribute the surplus brought about by cooperation, emphasizing the combination of efficiency and fairness. The surplus of cooperation should be distributed reasonably. Participants focus on long-term interests rather than immediate interests. Appropriate punishments to betrayers are the basis for long-term cooperation.

\subsection{Evolutionary game analysis and simulation between cooperatives, associations of water user and the government}

Practices at home and abroad show that the development of SWCP cooperative organizations cannot do without the support of governments at all levels. There is also a game relationship between the government and the small water conservancy project cooperative organization. The dynamic model of replication in evolutionary game theory is used to explore the behavioral laws of the government and farmer professional cooperatives in the evolutionary game.
The government's behavioral strategies are (participate, absent). The "participate" strategy is embodied in actively propagating the idea of cooperation, guiding farmers and other social forces to participate in the construction of small water conservancy projects, and providing financial and financial policy support actively to provide a good external environment for the development of cooperatives and water user associations. "Absent" mainly refers to the arbitrary intervention in the operation and management of cooperatives, associations of water user and other organizations, resulting in additional "rent-seeking" costs; or allowing them to fend for themselves and failing to actively create a good external environment. The strategies of SWCP cooperative organizations are (active development, passive development). "Active development" is embodied in making full use of the external environment to create more cooperation surplus, and "negative development" is embodied in internal management confusion and not expanding the organization actively.

If the government chooses the "participant" strategy, the government will obtain high social reputation benefits and local economic benefits I, but at a cost $\mathrm{C}$; if the government chooses the "absent" strategy, both reputation benefits and economic benefits will be zero. If the basic income of a professional farmer cooperative choosing a "passive development" strategy is R, under the condition of the government "acting", the cooperative's positive development income will increase by $\mathrm{r} 1$, and it will be able to obtain the government's support income f. If the government choose to be "absent", the cooperative will gain $\mathrm{r} 2$ for its active development $(\mathrm{r} 1>\mathrm{r} 2)$, but the cooperative will increase additional costs $d$ for development. Suppose that the probability that the government chooses the "act" strategy is $x$, and the probability of choosing the "inaction" strategy is $1-x$; the probability of a farmer cooperative organization choosing the "active development" strategy is y, and the probability of choosing a "negative development" strategy is $1-y$. The game payment matrix of governments and organizations is shown in the table below.

Table4. Game payment matrix between government and organization

\begin{tabular}{|c|c|c|c|}
\hline & & \multicolumn{2}{|c|}{ Organization(Cooperation, association) } \\
\hline & & Active development $\mathrm{y}$ & Passive development 1-y \\
\hline \multirow{3}{*}{ Government } & Participant $\mathrm{x}$ & $(\mathrm{I}-\mathrm{C}, \mathrm{R}+\mathrm{r} 1+\mathrm{f})$ & $(-\mathrm{C}, \mathrm{R}+\mathrm{f})$ \\
\cline { 2 - 4 } & Absent 1-x & $(0, \mathrm{R}+\mathrm{r} 2-\mathrm{d})$ & $(0, \mathrm{R})$ \\
\hline
\end{tabular}

Expected payment when the government chooses "Participant":

$$
\mathrm{U}_{11}=y((I-C)+(1-y)(-C)=y I-C
$$

Expected payment when the government chooses "Absent":

$$
\mathrm{U}_{12}=y(0)+(1-y)(0)=0
$$

Average expected payment of the government:

$$
\mathrm{U}_{1}=x \mathrm{U}_{11}+(1-x) \mathrm{U}_{12}=x(y I-C)
$$

Average expected payment of the organization:

$$
\mathrm{U}_{2}=y \mathrm{U}_{21}+(1-y) \mathrm{U}_{22}
$$

Therefore, the replication dynamic equations of the government and the organization in time $t$ are respectively:

$$
\begin{gathered}
\mathrm{F}(x)=\frac{d x}{d t}=x\left(\mathrm{U}_{11}-\mathrm{U}_{1}\right)=x(1-x)(y I-C) \\
\mathrm{F}(y)=\frac{d y}{d t}=y\left(\mathrm{U}_{21}-\mathrm{U}_{2}\right)=y(1-y)\left(r_{1} x-r_{2} x+d x+r_{2}-d\right)
\end{gathered}
$$

The solutions that the government and the organization to reach the stable evolutionary state can be obtained: $\mathrm{S}_{1}$ $(0,0), S_{2}(1,0), S_{3}(0,1), S_{4}(1,1), S_{5}\left[\left(r_{2}-d\right) /\left(r_{1}-\right.\right.$ $\left.\mathrm{r}_{2}+\mathrm{d}\right), C / \Pi$. According to the stability analysis of the corresponding Jacobian matrix, $\mathrm{S}_{1}$ and $\mathrm{S}_{4}$ are with local 
stability, corresponding to the evolutionary stability strategy of the total population. $\mathrm{S}_{2}$ and $\mathrm{S}_{5}$ are the unstable equilibrium points of the evolution system, and $S_{5}$ is the saddle point.

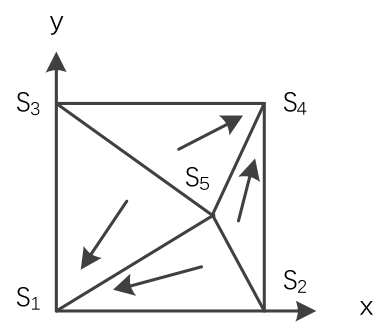

Fig 2. Evolutionary game diagram of government and organization

From the above figure, the broken line composed of points $S_{2}, S_{5}$ and $S_{3}$ is the dividing line for individuals to choose different strategies after the group dynamic evolution game reaches equilibrium. It divides the cooperative group evolution space into two regions $\mathrm{S}_{1} \mathrm{~S}_{2} \mathrm{~S}_{5} \mathrm{~S}_{3}$ and $\mathrm{S}_{3} \mathrm{~S}_{5} \mathrm{~S}_{2} \mathrm{~S}_{4}$. In the $\mathrm{S}_{1} \mathrm{~S}_{2} \mathrm{~S}_{5} \mathrm{~S}_{3}$ area, the system converges to the $\mathrm{S} 1$ point, and the (absent, passive development) strategy becomes an evolutionary stable strategy; in the area $\mathrm{S}_{3} \mathrm{~S}_{5} \mathrm{~S}_{2} \mathrm{~S}_{4}$, the system converges to the point $S_{4}$, and the (participant, active development) strategy is the only evolutionary stable strategy. It can be seen that the long-term game between government and organization will evolve in two completely opposite directions. In the above figure, how the government and organization choose their strategy depends on the size and relationship of the five parameters $d, r_{1}, r_{2}, C, I$, and I in saddle point $\mathrm{S}_{5}$. Among them: $\mathrm{d}$ represents the additional cost that the organization needs to increase in order to achieve development in the case of government "inaction"; r1 represents the additional benefits obtained by the organization's active development in the case of government "action"; $r_{2}$ represents the situation without government support The benefits that can be obtained by the active development of the organization represent the actual profitability of the organization's project; C represents the cost invested by the government because of "action"; $l$ represents the benefits that the government receives from choosing "participant". The following two important conclusions can be obtained through analysis:

First, government support is an important guarantee for the development of farmer cooperatives. The government should actively support the development of rural household cooperative organizations, increase policy incentives and capital supply, and reduce additional costs such as rent-seeking costs for organizations. Second, the government's choice of "participant" or "absent" depends on the government's own costs and benefits and the profitability of farmers' professional cooperatives. Farmer cooperative organizations look for good projects, actively seek development, and obtain government policy support and financial subsidies, which is conducive to promoting the development of professional farmer cooperatives.

\subsection{Analysis of the evolution of the property right structure of SWCPs under the game of each subject}

(1) The evolution of the property right structure under the conflict of demands between farmers and organizations

The conflicts of property rights between farmers and cooperatives, associations and other organizations are mainly resulted in the unreasonable allocation of property rights caused by conflicts between farmers' desire for cooperation and insufficient corporate resource integration capabilities. Whether the initial desire for cooperation is strong or not is a prerequisite for the success of the cooperative. If farmers have good expectations, they will generally actively participate in cooperation, actively invest in elements, and promote the integration of elements, so as to realize the complementation of resources between the participants and create more cooperation surplus. If the purpose of participating in cooperation is to take "a free ride" or "rent-seeking", after a long period of game, the behavior of negative cooperation will be learned and imitated, and the result of evolution is the end of cooperation. At the same time, cooperative leaders with entrepreneurial spirit are an important guarantee for the sound operation of cooperative organizations [17]. For ordinary farmers, they have long been accustomed to the family-based small-scale production model, and they lack the experience of largescale joint production, the resources to open up markets, the necessary technology, and the ability to grasp market information. It is necessary for the managers of cooperatives to integrate the resources of homogeneous farmers to realize resource conservation and the benefits of large-scale production and operation.

In the joint-stock management model, collective stocks are in a dominant position, and the shares of farmers affected by the smallholder economy are generally small. Due to the unequal status of investment subjects, a pattern of coexistence of rancher and small shareholders has been formed. Farmers and enterprises are unable to maintain and repair small water conservancy projects, and the benefits of the projects are declining, which affects the basic water demand and participation demands of farmers. The management and protection mode of small water conservancy projects under the joint-stock system is in urgent need of reform. The participatory management model promotes the separation of management rights and maintenance rights through the water user associations and Management Bureau of Small Water Conservancy Engineering. The water user association composed of farmers is mainly responsible for the maintenance of small water conservancy projects within its jurisdiction and exercises the right of maintenance. The Management Bureau of Small Water Conservancy Engineering, which is affiliated to the Water Resources Bureau, is mainly responsible for water supply services and exercise management power. The separation of management rights and maintenance rights in this mode can better solve the maintenance problems of small water conservancy projects and promote the transformation of government functions. 
(2) The evolution of the property right structure under the conflict of government and organization demands

The conflict between the government and the enterprise's demands is mainly reflected in the conflict between the government's demands for economic development and social stability and the enterprise's internal principal-agent model. The government attracts all investors to participate in the financing of small water conservancy projects through inductive investment, with a view to raising sufficient funds for the management and maintenance of small water conservancy projects. Under this investment model, government-invested collective stocks account for $60 \%$ of the total stocks and generally do not participate in dividends. Among the $40 \%$ of the shares of farmers, a small number of core members are the main investors of the cooperative and often act as the manager of the cooperative. A principal-agent relationship is essentially formed between the cooperative and the manager, with all members as the principal and the manager as the agent. If there is a principal-agent relationship, the principal should pay the remuneration of agent. In practice, most managers of small water conservancy engineering cooperatives do not receive remuneration, but serve other members "for free". On the one hand, a small number of core members are the main investors of the cooperative, and self-entrustment can avoid the moral hazard caused by entrusting others to act as an agent; On the other hand, the managerial compensation is difficult to value, and ordinary members are not willing to pay high salaries to entrust an agent with the status of "core member" By. Therefore, the human capital contribution of the agent cannot get due remuneration and is in a state of "fuzzy" property rights. This "fuzzy" state of property rights has become the main factor restricting the development of small water conservancy projects. If it cannot be properly resolved, it will eventually fall into the peasant cooperation dilemma and conflict with the government's demands.

The conflict between the principal and the agent's benefit distribution model highlights the importance of the incentive mechanism. According to the analysis results of the evolutionary game model, under the premise that the benefits of cooperation are greater than the input costs, it is necessary to consider not only the return of the elements of cooperation, but also the "pro-poor principle" and the interests of "ordinary farmers". To achieve a reasonable distribution, power must be escorted by checks and balances to achieve an evolutionary stable equilibrium from "Pareto improvement" to "Pareto optimality" and "active cooperation". Second, the internal cost allocation of cooperatives should be reasonable. There are extensive trust-agent relationships within cooperatives, resulting in asymmetric information among members. At this time, the size of the specific investment cost is often used to judge whether the parties have the willingness to actively participate in the cooperation. Effective investment is an integral part of the cooperation. A credible promise. Costs should be shared between the two parties involved in the game. If cost allocation is asymmetric, short-sighted behaviors such as opportunism and "free-riding" will occur, which is not conducive to the formation of longterm cooperative relationships. Finally, incentives and constraints must be reasonable. The normal benefits of participating in cooperation plus the total benefits of the incentive and restraint mechanism must be greater than the total costs of active cooperation, and the incremental benefits of the incentive and restraint mechanism must not be less than the incremental costs of participating in the cooperative. Otherwise, the incentive and restraint mechanism will not take effect.

\section{Conclusion}

In order to explore the evolution process of the property right structure of small water conservancy projects under the condition of conflicting demands of multiple stakeholders, this paper started with the game model of each stakeholder in the SWCPs, and used the evolutionary game theory model to simulate and analyze the game behavior of each body. An in-depth analysis of the resulting evolution of property rights was conducted. Finally, the following conclusions are drawn:

(1) Farmer cooperative organizations should meet the interests and practical needs of farmers, strengthen the propaganda of cooperative ideas and the cultivation of cooperative spirit, deepen their cognition of professional cooperatives, and motivate the desire of cooperation. In the organization, design incentive and restraint mechanisms to increase farmers' income expectations, which positively affects the cooperative behavior of farmers and contributes to good results.

(2) Farmers and cooperative organizations should share costs and distribute cooperative surpluses together reasonably. This is conducive to attracting the investment of ordinary farmers to form a good property right structure, can strengthen the mutual connection between cooperative members, and form a community of both interest and risk.

(3) The government should support the development of rural household cooperative organizations actively, increase policy incentives and capital supply, and reduce additional costs such as rent-seeking costs for organizations. Farmer cooperative organizations should look for good projects, seek for development actively, and obtain government policy support and financial subsidies, which is conducive to promoting the development of professional farmer cooperatives.

This paper combined simulation analysis with theoretical research, proposed a multi-agent evolutionary game model for small water conservancy projects under appeal conflicts of stakeholders, and simulated and analyzed the decisions of all parties to the conflicting appeals. The research conclusions obtained are helpful for the design of small water conservancy projects. The structure of property rights has a certain reference. Due to the lack of actual data, in future research, the research has its own limitations. Further data will be collected and the model will be revised, then the understanding of the evolutionary law of the property rights structure of SWCPs under the conflict of multi-stakeholder appeals will be more accurate. 


\section{References}

1. Wang Yahua. (2013) The Reform of China Water Users Association: A Review from the Perspective of Policy Implementation. Management World, 6:6171.J. Clerk Maxwell, A Treatise on Electricity and Magnetism, 3rd ed., vol. 2. Oxford: Clarendon, 1892, pp.68-73.

2. Liu Hui. (2014) An Empirical Analysis of the Impact of Institutional Rules on the Performance of Smallscale Farmland Water Conservancy Governance: Based on an Investigation of 192 Small-scale Farmland Water Conservancy Facilities in Hunan Province. Agricultural Technology Economy 12:110117.

3. Li Yiheng. (2018) The Primary and Secondary Issues of Agricultural Infrastructure Property Rights - Take Small Farmland Water Conservancy Projects as an Example. Law Forum, 33(02):101-108.

4. Smith J M, Price GR. (1973) The logic of animal conflict. Nature, 246(5427): 15-18.

5. Weibull. ( 2006 ) Evolutionary Game Theory. Shanghai People's Publishing House, Shanghai.

6. Aoki. (2001) Comparative Institutional Analysis. Shanghai Far East Publishing House, Shanghai.

7. Friedman D. (1998) On Economic Applications of Evolutionary Game Theory. Journal of Evolutionary Economics, 8:15-43.

8. Kosfeld M. (2002) Why Shops Close Again: An Evolutionary Perspective on the Deregulation of Shopping Hours. European Economic Review, 46: 51-72.

9. Nyborg K, Rege M. (2003) On Social Norms: The Evolution of Considerate Smoking Behavior. Journal of Economic Behavior \& Organization, 52: 323-340.

10. Jasmina A, John L. (2004) Scaling up Learning Models in Public Good Games. Journal of Public Economic Theory, 6(2): 203-238.

11. Daniel G, Arce M, Todd S. (2005) The Dilemma of the Prisoners'Dilemmas. KYKLOS, 58(1): 3-24.

12. Josef Hofbauera, William H, Sandholmb. (2007) Evolution in games with randomly disturbed payoffs[J]. Journal of Economic Theory, 132: 47-69.

13. Han Xiaohua, Xue Shengjia. (2007) Analysis of Psychological Contract Based on Evolutionary Game. Enterprise Economy, 9:33-35.

14. Feng Lei, Jiang Li,Zheng wenbo. (2019)Cognition, Informal Constraints and Institutional Changes: Based on the Perspective of Evolutionary Game. Comparison of Economic and Social Systems, 2:165177.

15. Aoki, Okuno Fujiwara. Translated by Wei Jianing and others, (2005) Comparative Institutional Analysis of Economic System (Revised Edition). China Development Press, Beijing.
16. Selten R. ( 1998 ) Features of experimentally observed bounded rationality. European Economic Review, 42:413-436.

17. Yuan Peng. (2001)Research on Farmer Cooperative Organizations in the Process of Chinese Rural Marketization. Chinese Social Sciences, 06:63-73. 